Article

\title{
Toward an Understanding of the Formation and Desolvation of Methanol Solvate, and Structure of Methanolysis Product: A Case Study of Nicosulfuron
}

\author{
Huaxiang Zhu ${ }^{1}{ }^{1}$, Bei Zhang ${ }^{1}$, Di Wu ${ }^{1}$, Xiaowei Cheng ${ }^{1}$, Guiping $\mathrm{Li}^{1}{ }^{1}$, Jun $\mathrm{Xu}^{3}$, Lina Zhou ${ }^{1,2}$ \\ and Wei Chen $1,2, *$ (D) \\ 1 National Engineering Research Center of Industrial Crystallization Technology, School of Chemical \\ Engineering and Technology, Tianjin University, Tianjin 300072, China; zhuhuaxiang168@163.com (H.Z.); \\ zhangbei168168@163.com (B.Z.); wudi1008@tju.edu.cn (D.W.); chengxiaowei@tju.edu.cn (X.C.); \\ ligp@tju.edu.cn (G.L.); Linazhou@tju.edu.cn (L.Z.) \\ 2 Collaborative Innovation Center of Chemical Science and Engineering, Tianjin University, \\ Tianjin 300072, China \\ 3 Health Science Platform, Tianjin University, Tianjin 300072, China; Jun.xu@tju.edu.cn \\ * Correspondence: chenwei@tju.edu.cn; Tel.: +86-22-2740-5754
}

Received: 28 January 2020; Accepted: 26 February 2020; Published: 1 March 2020

\begin{abstract}
Nicosulfuron (NS) is a widely used sulfonylurea herbicide because of its high selectivity, broad spectrum of herbicide activity, and excellent performance. In this work, nicosulfuron methanol solvate (NS-MeOH) and [[3-[(Dimethylamino)carbonyl]-2-pyridinyl]sulfonyl]carbamic acid methyl ester (PCM) as a product of methanolysis of NS were obtained. Both of their structures were determined by a single crystal $X$-ray diffraction. A broad range of analytical techniques was applied to characterize the NS-MeOH, such as Powder X-ray diffraction (PXRD), thermogravimetric analysis (TGA), differential scanning calorimetry (DSC), and hot stage microscopy (HSM). Combined with the analysis of the Independent gradient model (IGM), Atom-in-molecules (AIM), and Hirshfeld surface (HS), direct insights into the role of solvent played in the formation of NS-MeOH and the mechanism of solid-to-solid phase transformation of NS-MeOH could be obtained. In addition, the aqueous solubility of NS was improved through the formation of NS-MeOH. A systematic investigation of herbicidal activity of NS and PCM was carried out. It was found that NS and NS-MeOH had similar herbicidal activities at the experimental concentrations while PCM exhibited significantly lower activity. It was suggested that methanolysis of the sulfonylurea bridge in the NS molecule exerted a great influence on the herbicidal activity.
\end{abstract}

Keywords: nicosulfuron; hydrogen bond; methanol solvate; desolvation; methanolysis

\section{Introduction}

Solvates are crystal forms with solvents incorporated into the crystal structure of the host compound in a stoichiometric or non-stoichiometric ratio [1], which are also identified as pseudopolymorphs [2]. In the pharmaceutical industry, necessary solvents or solvent vapors are involved in various unit operations such as mixing and spray drying. During these processes, the active pharmaceutical ingredient (API) is in close contact with the solvents, and the corresponding solvates may form under certain conditions. Due to the differences in the solvates' structure based on the packing arrangement [3], molecular conformation [4,5], and intermolecular interaction, they may give rise to great variation in physicochemical properties such as solubility, stability, dissolution, and bioavailability. It will further exert great influences on the processing of API into drug products [5,6]. Therefore, the study on solvate behavior is of great value, which can not only provide a theoretical basis for the selection of optimal 
solid forms, but also serve for the polymorphic control [7] and optimization of the products as a basic method [8].

To get a better understanding of solvate formation, more attention needs to be paid to the role of solvent molecules. Two situations should be considered regarding it [9]: (a) the incorporation of the solvent molecules compensates the imbalance between the hydrogen bond donor and acceptor sites [10-12] of the host molecules and contributes to stronger intermolecular interaction, and (b) the solvent molecules embedded in lattice reduce the void space and increase the packing efficiency. Usually, both of these driving forces take effect in the formation of solvate along with a reduction of crystal-free energy [13].

Solvate desolvation [14] has been identified as an effective approach to control polymorphic forms. Sometimes, new polymorphic forms could be obtained, which might be unprocurable by common crystallization methods. Berzins et al. [15] revealed that dehydration of fine benperidol dihydrate powder at $30^{\circ} \mathrm{C}$, over $\mathrm{P}_{2} \mathrm{O}_{5}$, resulted in the formation of new polymorph $\mathrm{V}$. Moreover, polymorph $\mathrm{V}$ could be transformed to new polymorph IV at an elevated temperature (above $40^{\circ} \mathrm{C}$ ). In addition, Aitipamula et al. [2] found that desolvation of the sulfamerazine solvates at reduced pressure and at $90{ }^{\circ} \mathrm{C}$ converted all the solvates to Form I. Li et al. [16] observed that carbamazepine dihydrate was converted to amorphous upon dehydration at $45^{\circ} \mathrm{C}$, which could recrystallize into anhydrous $\gamma$-CBZ (carbamazepine) upon further heating (at $86^{\circ} \mathrm{C}$ ). Thereby, comprehensive knowledge of desolvation behavior is conducive to grasp the mechanism of solid-state reactions and further control the crystal form of the drug substances.

Nicosulfuron (2[(4,6-dimethoxypyrimidine-2-yl)aminocarbonyl]-aminosulfonyl-N,N-dimethyl-3-pyridinecarboxam NS, Figure 1a) in its anhydrous form Ia has been reported in a patent [17]. It is widely recognized as a potent sulfonylurea herbicide employed as getting rid of weeds in corn. Flexible conformation along with several donor and acceptor sites in the NS molecule provides the potential possibility to exhibit polymorphism. To date, several solvates and solvent-free forms of NS have been reported. Liu [18] et al. found six different NS solvates and four different solvent-free forms. However, only the structures of form II, S1, and S3 were solved. Chen [19] characterized the structure and revealed a gas-phase-mediated transformation of NS DMF (N,N-Dimethylformamide) solvate and hydrate. The crystallographic data of all known polymorphs based on NS (II, S1, S3, hydrate, and DMF solvate) was summarized in Table S1. In addition, PCM ([[3-[(Dimethylamino)carbonyl]-2-pyridinyl]sulfonyl]carbamic acid methyl ester, Figure 1b) was mentioned as a product of alcoholysis of NS by Sabadie [20]. So far, no research had revealed its structure and relevant polymorphs based on PCM. In our work, the single crystal structure of PCM was elucidated for the first time.

The aims of this study are (a) to provide a comprehensive knowledge of the role of solvent molecules in the formation of solvates and the influence of structure exerted on the physicochemical property such as solubility and herbicidal activity, (b) to evaluate the strength of the main H-bonds in the NS-MeOH and calculate the corresponding bonding energy, (c) to investigate the solid-to-solid phase transformation of NS-MeOH upon desolvation and give direct insight on the mechanism of desolvation, and (d) to analyze the methanolysis reaction and herbicidal activity of a corresponding methanolysis product. 
<smiles>COc1cc(OC)nc(NC(=O)NS(=O)(=O)c2ncccc2C(=O)N(C)C)n1</smiles>

(a)<smiles>COC(=O)NS(=O)(=O)c1ncccc1C(=O)N(C)C</smiles>

(b)

Figure 1. Chemical structure of (a) nicosulfuron (NS) and (b) [[3-[(Dimethylamino)carbonyl]-2pyridinyl]sulfonyl]carbamic acid methyl (PCM).

\section{Experimental Section}

\subsection{Materials}

NS with the analytical standard (identified as form Ia, Figure 2) was purchased from Wuhan Yuancheng Gongchuang Co., Ltd (Wuhan, China). All solvents with an analytical grade were obtained from Tianjin Jiangtian Chemical Co. (Tianjin, China) and used without further purification.

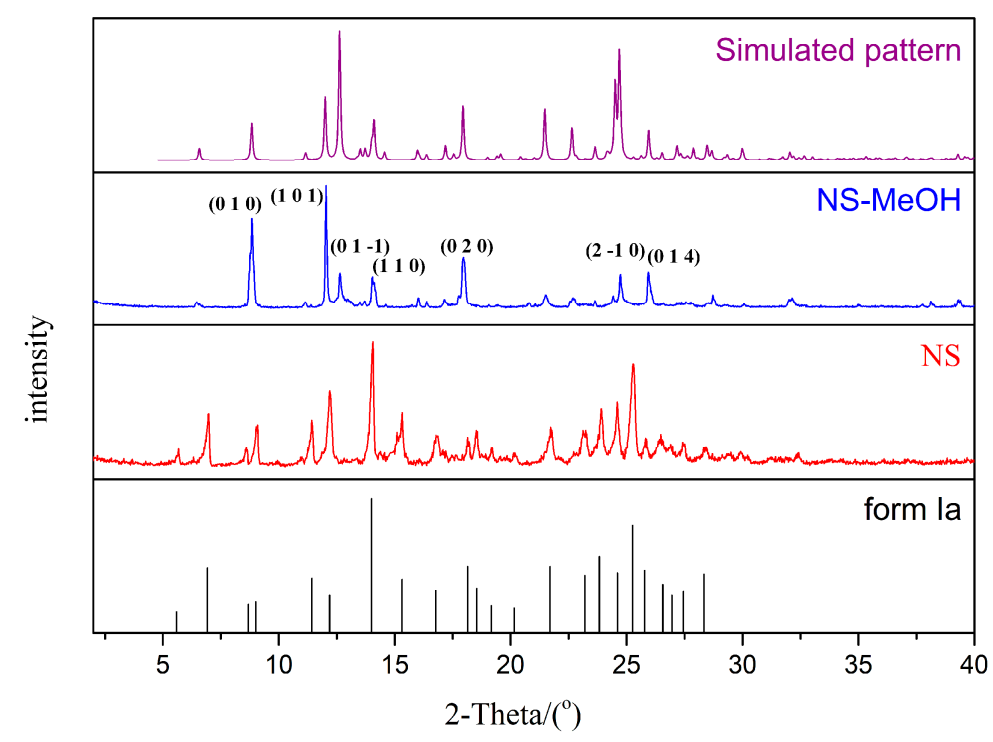

Figure 2. Powder X-ray diffraction (PXRD) patterns of form Ia, nicosulfuron (NS), NS-MeOH, and simulated pattern of NS-MeOH. 


\subsection{Preparation of NS-MeOH and PCM}

A $0.008 \mathrm{~g}$ sample of NS was dissolved in a glass vial with $2 \mathrm{~mL}$ of acetone. Then, $2 \mathrm{~mL}$ of methanol was slowly added as an anti-solvent. The glass vial was sealed and placed motionlessly in the refrigerator at $5{ }^{\circ} \mathrm{C}$. Then NS-MeOH was formed $24 \mathrm{~h}$ later. The NS-MeOH was filtered and dried in vacuum, while the filtrate was used to obtain the single crystal by slow evaporation at the same temperature.

An excess of NS ( $0.01 \mathrm{~g})$ was dissolved in methanol in $10 \mathrm{~mL}$ glass, which was heated under reflux at the temperature of the boiling point of methanol. After the solution was cooled to room temperature, the saturated solution was then filtered by a $0.22 \mu \mathrm{m}$ PTFE (Poly tetra fluoroethylene) membrane filter. Lastly, the filtered solution was placed in the refrigerator at $-20^{\circ} \mathrm{C}$, and single crystal of PCM was obtained one week later.

\subsection{Thermogravimetric Analysis (TGA)}

Thermogravimetric analysis was performed using a Mettler TGA/DSC 1 (STARe, Mettler, Switzerland) instrument. The samples of NS-MeOH were heated under a nitrogen purge flow rate of $20 \mathrm{~mL} / \mathrm{min}$ at scan rates of $10^{\circ} \mathrm{C} / \mathrm{min}$.

\subsection{Differential Scanning Calorimetry (DSC)}

Differential scanning calorimetry was carried out using a Mettler DSC 1 (STARe, Mettler, Switzerland) instrument calibrated by indium and tin. The sample of NS-MeOH was heated at a scan rate of $10^{\circ} \mathrm{C} / \mathrm{min}$ under a nitrogen purge flow of $50 \mathrm{~mL} / \mathrm{min}$.

\subsection{Powder X-ray Diffraction (PXRD)}

Powder X-ray diffraction was conducted on a X-ray diffractometer (D/MAX 2500, Rigaku, Japan) using $\mathrm{Cu} \mathrm{K \alpha}$ radiation $(\lambda=1.54184 \AA$ ) with a graphite monochromator at $40 \mathrm{kV}$ and $100 \mathrm{~mA}$. The samples were measured at an ambient temperature in the $2 \theta$ range of $2^{\circ}-40^{\circ}$ with a scan rate of $8^{\circ} / \mathrm{min}$.

\subsection{Single Crystal X-ray Diffraction (SCXRD)}

Single crystal X-ray diffraction (SCXRD) measurement of NS-MeOH was conducted on a diffractometer (Saturn 70 CCD, Rigaku, Japan) using Mo K $\alpha$ radiation $(\lambda=0.71073 \AA$ ) with a graphite monochromator while SCXRD of PCM was measured by diffractometer (007HF XtaLAB P20, Rigaku, Japan) using Cu K $\alpha$ radiation $(\lambda=1.54184 \AA$ ) with a graphite monochromator. Integration and scaling of the intensity data were both accomplished using the SAINT program (Dephi corporation, USA). The structures of NS-MeOH and PCM were solved using SHELEX 2014 (George Sheldrick, Gottingen University, Germany) [21]. Refinement was conducted by full-matrix least-squares using SHELEX 2014 [22] implemented in Olex2-1.2 (O.Dolomannov, Durham University, UK) [23]. Data were both corrected for the effects of absorption using SADABS in the SAINT program. All non-hydrogen atoms were refined anisotropically. Hydrogen atoms on $\mathrm{N}$ or $\mathrm{O}$ atoms were located in difference maps. All hydrogen atoms bound to carbon atoms were generated by a riding model in idealised geometries and their positions were refined with $\mathrm{U}_{\text {iso }}(\mathrm{H})=1.5 \mathrm{U}_{\text {eq }}(\mathrm{C})$ for $-\mathrm{CH}_{3}$ groups and $\mathrm{U}_{\text {iso }}(\mathrm{H})=1.2 \mathrm{U}_{\text {eq }}(\mathrm{C})$ for other $\mathrm{H}$ atoms. The packing diagrams of crystal structures of NS-MeOH and PCM were obtained by Mercury 4.1.0 software (Cambridge Structural Database, Cambridge, UK) [24].

\subsection{Hot Stage Microscopy (HSM)}

The HSM experiment was performed by using a polarizing microscope (Olympus BX-51, Tokyo, Japan) combined with a DSC600 hot stage Linkam system at a heating rate of $10^{\circ} \mathrm{C} / \mathrm{min}$. 


\subsection{Dissolution Measurement}

The powder dissolution experiment of NS and NS-MeOH were conducted in a dissolution test (RC-6, Guangzhou Hangxin scientific instrument Co., Guangzhou, China) analyzer for $270 \mathrm{~min}$ at $25^{\circ} \mathrm{C}$. Accurate $0.3000 \mathrm{~g}$ samples were added to dissolution vessels containing $900 \mathrm{~mL}$ of pure water. All the samplings were analysed using a spectrophotometer (U-3010, HITACHI, Japan). Before measuring the concentration of samplings, they were filtered by $0.22 \mu \mathrm{m}$ PTFE membrane filters and then diluted 10-fold with pure water. The concentration was determined for three times by a UV standard curve $\left(y=0.0412 x+0.0162, R^{2}=0.9992\right.$, Figure S1) at $25^{\circ} \mathrm{C}$, and the mean value was used for further study.

\subsection{Herbicidal Activity}

The pot test was applied to investigate the herbicidal activities of NS, NS-MeOH, and PCM against E. crusgalli (Echinochloa crusgalli Beauv), S. viridis (Setariaviridis Beauv), D. sanguinalis (Digitariasanguinalis Scop), and A. theophrasti (Abutilon theophrasti Medicus) by postemergence foliar spray processing at dosages of 37.5 and $150 \mathrm{~g}$ a.i./ha, respectively [25].

\subsection{Computational Details}

The geometry optimization of NS-MeOH was performed in CASTEP built in Materials Studio 60 (Accelrys, USA) [26] with relaxing positions of all atoms by plane-waves density functional calculations. The unit cell parameters were fixed during the optimization. All calculations were performed using the generalized gradient approximation (GGA) by PBE (Perdew-Burke-Ernzerhof) as exchange-correlation density functional and ultra-soft pseudopotentials [27] with the addition of Grimme's D2 dispersion correction [28]. Energy cutoff used for a plane wave basis set was set to $780 \mathrm{eV}$. Brillouin zone integration was performed using a discrete $2 \times 2 \times 2 \mathrm{k}$-point sampling for a primitive cell. The energy threshold, force threshold, and atomic displacements threshold for structural relaxation were set to $10^{-5} \mathrm{eV}, 5 \times 10^{-2} \mathrm{eV} / \AA$, and $10^{-3} \AA$, respectively. Two NS-methanol molecular pairs corresponding

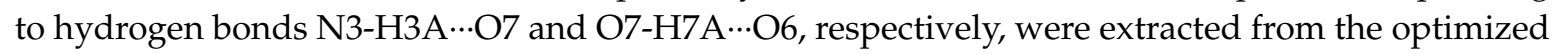
crystal structure. Their wave functions were separately generated by running single point energy calculations at the M062X-D3/6-311++G (2d, p) level [29-31] using the Gaussian 09 program [32] in the gas phase, and the calculations were further performed in methanol using the SMD (Solvation Model Based on Density) model [33] to explore the impacts of solvent on the hydrogen bonding systems. Then, the wave functions generated by Gaussian 09 were further analysed through Atom-in-molecules (AIM) analysis performed by Multiwfn 3.6 [34] and visualization program VMD (Visual Molecular Dynamics) 1.9.3 [35]. Independent gradient model (IGM) analysis was also performed using Multiwfn 3.6 and visualization program VMD 1.9.3. In addition, according to the criterion proposed by Emamian and $\mathrm{Lu}$ et al. [36], the binding energy $(\mathrm{BE}, \mathrm{kcal} / \mathrm{mol})$ for neutral complexes may be calculated by the following equation,

$$
B E=-223.08 \times \rho_{B C P}+0.7423,
$$

where $\rho_{B C P}$ is the value of the electron density at the bond critical points (BCPs).

\section{Results and Discussion}

\subsection{Structual Analysis}

As shown in Figure 2, The PXRD pattern of NS-MeOH showed new peaks at $12.8^{\circ}, 14.3^{\circ}, 16.2^{\circ}$, $17.4^{\circ}$, and $22.8^{\circ}$, which exhibited clear differences compared to the pattern of pure NS. These unique peaks indicated that NS-MeOH was a new crystal form. Moreover, good agreement between the experimental pattern and a simulated pattern also confirmed the identity of the new phase and high crystallinity of NS-MeOH. In addition, the structure of NS-MeOH and PCM were determined by SCXRD. The crystallographic parameters of two crystal structures were summarized in Table 1. Hydrogen bonds of the obtained crystals were listed in Table 2. 
Table 1. Crystallographic data of NS-MeOH and [[3-[(Dimethylamino)carbonyl]-2-pyridinyl]sulfonyl]carbamic acid methyl (PCM).

\begin{tabular}{|c|c|c|}
\hline Parameters & NS-MeOH & PCM \\
\hline Formula & $\mathrm{C}_{15} \mathrm{H}_{18} \mathrm{~N}_{6} \mathrm{O}_{6} \mathrm{~S} \cdot \mathrm{CH}_{4} \mathrm{O}$ & $\mathrm{C}_{10} \mathrm{H}_{13} \mathrm{~N}_{3} \mathrm{O}_{5} \mathrm{~S}$ \\
\hline Formula weight & 442.46 & 287.29 \\
\hline Crystal system & triclinic & monoclinic \\
\hline Space group & $\mathrm{P}-1$ & $\mathrm{P} 2_{1} / \mathrm{n}$ \\
\hline Temperature/K & $293(2)$ & 199.99(10) \\
\hline Radiation type & Mo K $\alpha$ & $\mathrm{Cu} \mathrm{K} \alpha$ \\
\hline Wavelength/A & 0.71073 & 1.54184 \\
\hline $\mathrm{a} / \AA$ & $7.918(16)$ & $8.531(1)$ \\
\hline $\mathrm{b} / \AA$ & $10.255(2)$ & $10.029(1)$ \\
\hline$c / \AA$ & $13.859(3)$ & $15.212(1)$ \\
\hline$\alpha /{ }^{o}$ & $72.19(3)$ & 90.000 \\
\hline$\beta /{ }^{\circ}$ & $79.14(4)$ & $102.860(1)$ \\
\hline$\gamma /{ }^{\mathrm{o}}$ & $85.00(4)$ & 90.000 \\
\hline Volume $/ \AA^{3}$ & 1051.641(4) & $1268.86(2)$ \\
\hline Z & 2 & 4 \\
\hline \multirow[t]{2}{*}{$\theta$ range/ ${ }^{\circ}$} & $3.1-27.5$ & $5.3-76.8$ \\
\hline & $-10 \leq h \leq 8$ & $-10 \leq \mathrm{h} \leq 10$ \\
\hline \multirow[t]{2}{*}{ Index ranges } & $-13 \leq \mathrm{k} \leq 13$ & $-12 \leq \mathrm{k} \leq 11$ \\
\hline & $-17 \leq 1 \leq 17$ & $-18 \leq 1 \leq 19$ \\
\hline Density $/ \mathrm{g} \cdot \mathrm{cm}^{-3}$ & 1.397 & 1.504 \\
\hline $\mathrm{R}_{\text {int }}$ & 0.0398 & 0.0304 \\
\hline $\mathrm{R}_{1}[\mathrm{I}>2 \sigma(\mathrm{I})]$ & 0.054 & 0.0297 \\
\hline$\omega R_{2}$ & 0.1438 & 0.0865 \\
\hline goodness-of-fit & 1.07 & 1.0762 \\
\hline CCDC No. & 1865250 & 1894251 \\
\hline Color & colorless & colorless \\
\hline Shape & block & irregular \\
\hline
\end{tabular}

Table 2. Hydrogen bonds of NS-MeOH and PCM.

\begin{tabular}{|c|c|c|c|c|c|}
\hline Compound & 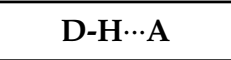 & $\mathrm{d}(\mathrm{D}-\mathrm{H}) / \AA$ & $\mathrm{d}(\mathrm{H} \cdots \mathrm{A}) / \AA$ & $\mathrm{d}(\mathrm{D} \cdots \mathrm{A}) / \AA$ & $\angle$ (DHA) $/^{\circ}$ \\
\hline \multirow{3}{*}{ NS-MeOH ${ }^{a}$} & N4-H4B ‥N2 & 0.86 & 2.00 & $2.629(2)$ & 129 \\
\hline & N3-H3A‥O7 & 0.86 & 1.97 & $2.821(3)$ & 169 \\
\hline & O7-H7A $\cdots$ O6 & $0.89(3)$ & $1.82(3)$ & $2.696(3)$ & $169(3)$ \\
\hline $\mathrm{PCM}^{\mathrm{b}}$ & N11-H11‥O15 & $0.85(18)$ & $1.91(18)$ & $2.755(16)$ & $173(2)$ \\
\hline
\end{tabular}

${ }^{\text {a }}$ Symmetry transformations used to generate equivalent atoms: $-\mathrm{x},-\mathrm{y},-\mathrm{z} .{ }^{\mathrm{b}}$ Symmetry transformations used to generate equivalent atoms: (1) $1 / 2-x, 1 / 2+y, 1 / 2-z$. (2) $-x,-y,-z$. (3) $1 / 2+x, 1 / 2-y, 1 / 2+z$.

NS-MeOH crystallizes in a triclinic crystal system with the group of $\mathrm{P}-1$, and the asymmetric unit contains one NS molecule and one methanol molecule (Figure S2). In the structure of NS-MeOH,

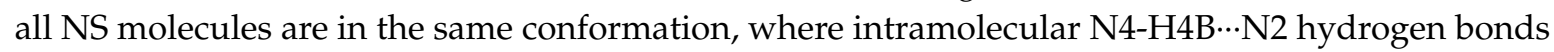
connect the pyrimidine ring to the sulfonylurea bridge so as to stabilize the structure of NS molecules. Furthermore, methanol molecules are connected to transition-related NS molecules by significant

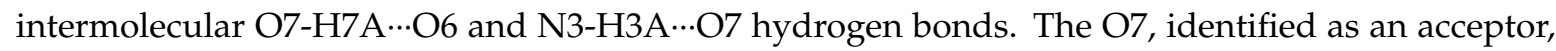
hydroxy group of the methanol interacts with the N3 imino group of the urea linking in a neighbouring NS molecule. Meanwhile, the O7, deemed to be a donor, interacts with the $\mathrm{O} 6$ carbonyl group of the other adjacent NS molecule. These two contacts aggregate the molecules into a zigzag chain along the crystallographic $b$ axis. Then, chains are connected through weak interactions to form the final network packing patterns (Figure 3a). In general, incorporation of the methanol molecule into the crystalline lattice of NS leads to more H-bond donor sites and acceptor sites, which provides potential intermolecular interaction to rearrange the intermolecular hydrogen bond pattern (Figure $3 b$ ). In addition, for a better understanding of the influence of methanol molecules on the crystal structure, 
the overlays of NS conformational molecules in NS-MeOH and other solved solvates were obtained. It was noteworthy that intermolecular interactions such as hydrogen bonds and van der Waals interactions, conformations, and packing motifs influenced each other. Furthermore, polymorphs with a larger number of symmetry-independent molecules (high $Z^{\prime}$ ) were more likely to lead to different conformations of these symmetry-independent molecules [37,38]. As shown in Figure 4, the results indicated a significant conformational difference between the NS molecule in NS-MeOH and that in other solved solvates. When compared with NS-MeOH, the different conformations of NS molecules in form II, S1 and hydrate could be ascribed to a high $\mathrm{Z}^{\prime}$ and complicated interactions. The acetonitrile molecules filled in a cage-shape structure mainly interacted with NS molecules through van der Waals interactions in form S3 while methanol molecules in NS-MeOH formed hydrogen bonds with NS molecules. The discrepancy in intermolecular interactions led to different conformations of NS. In addition, NS and methanol molecules formed zigzag chains by H-bonds in NS-MeOH, while heterodimers formed by NS and DMF molecules through H-bonds connected to each other by weak interaction in DMF solvate. Thus, different interactions between solvents and NS molecules combined with different packing motifs led to the final differences in conformations of NS molecules in all solved solvates.

PCM crystalizes in a monoclinic crystal system with a group of $\mathrm{P} 21 / \mathrm{n}$, and the asymmetric unit contains one PCM molecules (Figure S3). In the structure of PCM, the N11-H11 ‥O15 H-bond is formed by the hydrogen atom in the amine bond with one carbonyl oxygen atom of an adjacent PCM molecule. As a result, a zigzag chain along the $b$ axis is formed through adjacent molecules linked head-to-tail (Figure 5a). Then, chains are connected through the dispersion force shown hereafter, which results in the final packing motif (Figure $5 b$ ).

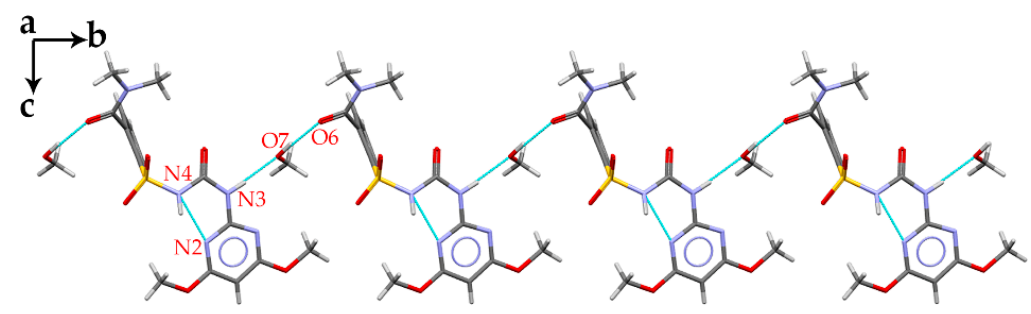

(a)

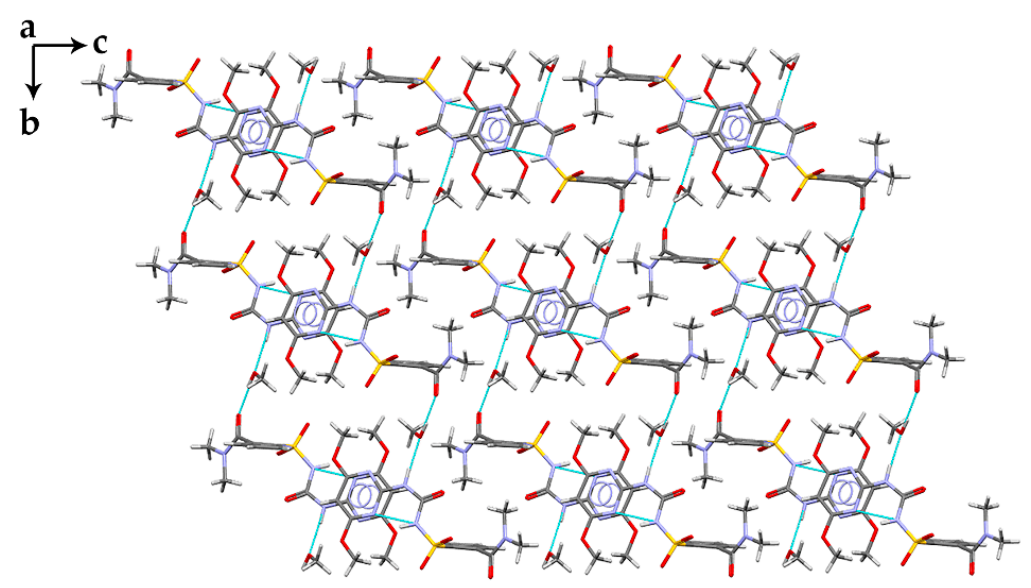

(b)

Figure 3. (a) 1-D chain formed by the hydrogen bonds along the b axis in NS-MeOH. (b) Packing motifs formed by the hydrogen bonds in NS-MeOH. 


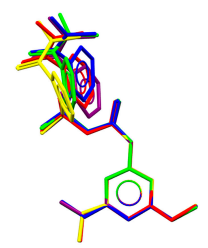

(a)

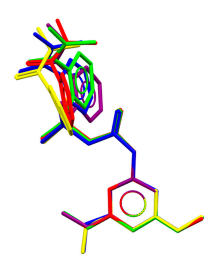

(d)

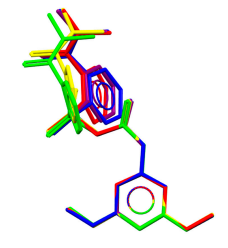

(b)

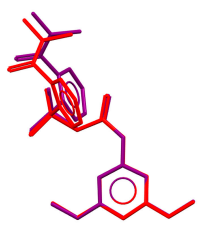

(e)

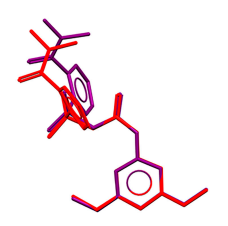

(c)

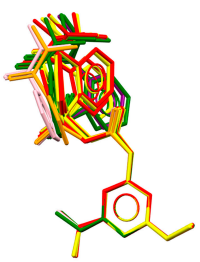

(f)

Figure 4. Overlay of the NS conformational molecule in NS-MeOH (purple) with (a) four different conformations of NS molecules in II (red, green, yellow, and blue), (b) four different conformations of NS molecules in S1 (red, green, yellow, and blue), (c) NS conformational molecule in S3 (red), (d) four different conformations of NS molecules in hydrate (red, green, yellow, and blue), (e) NS conformational molecule in DMF solvate (red), and (f) all different conformations of NS molecules in II (red), S1 (green), S3 (pink), hydrate (yellow), and DMF solvate (orange). H atoms are hidden for clarity.

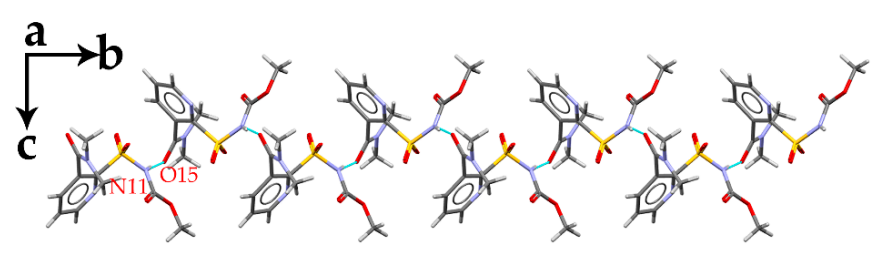

(a)

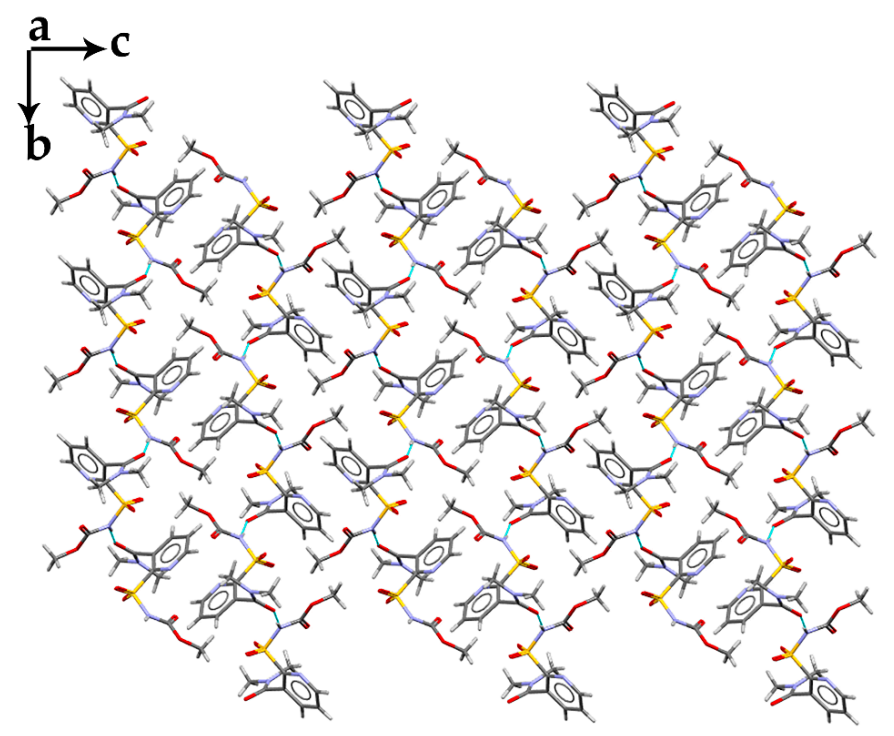

(b)

Figure 5. (a) 1-D chain formed by the hydrogen bonds along the $\mathrm{b}$ axis in [[3-[(Dimethylamino) carbonyl]-2-pyridinyl]sulfonyl]carbamic acid methyl (PCM). (b) Packing motifs formed by the hydrogen bonds in PCM. 


\subsection{Independent Gradient Model (IGM) Analysis}

Independent gradient model (IGM) [39] is a novel computational approach that lay more emphasis on non-covalent features. VMD plots on the basis of IGM analysis provide immediate insight in intermolecular interaction with corresponding colored ellipsoids, where the green part of the ellipsoid represents the dispersion force and the blue part is electrostatic force. To shed some light on the relationship between packing motifs and intermolecular interactions, molecules in the crystal were analyzed by IGM. As shown in Figure 6a, the results indicated that it had both electrostatic and dispersive effects on the intermolecular interactions between NS molecules and methanol molecules. However, the intermolecular interactions of two NS molecules were mainly dispersive, which identified two zigzag chains formed by an H-bond interaction between NS and methanol that were packed through a weak interaction. Similarly, adjacent PCM molecules forming zigzag chains were connected through electrostatic forces, and the two PCM molecules in the unit cell were primarily dispersive. It contributed to explaining that two chains bonded closely to form the final packing patterns in Figure $6 \mathrm{~b}$.

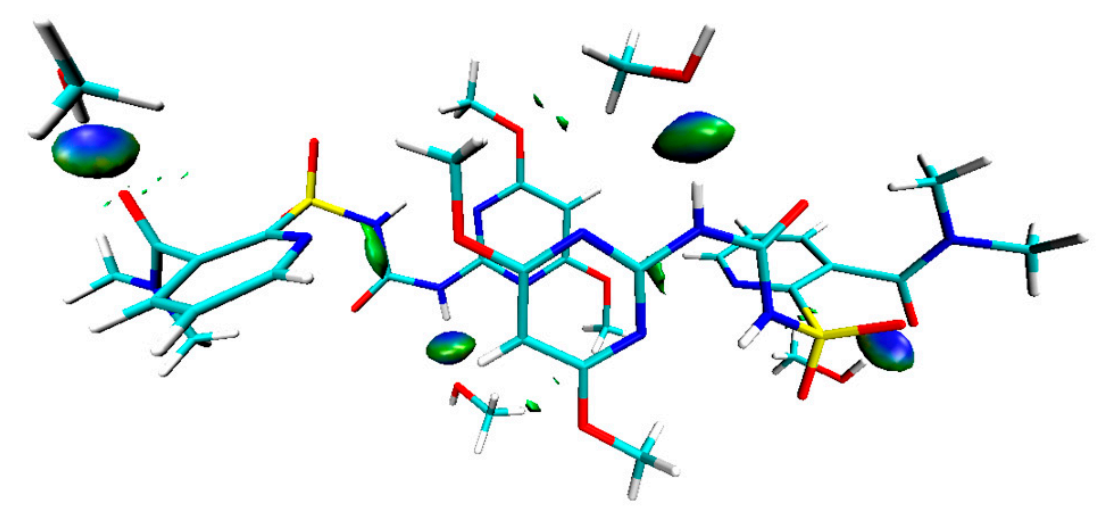

(a)

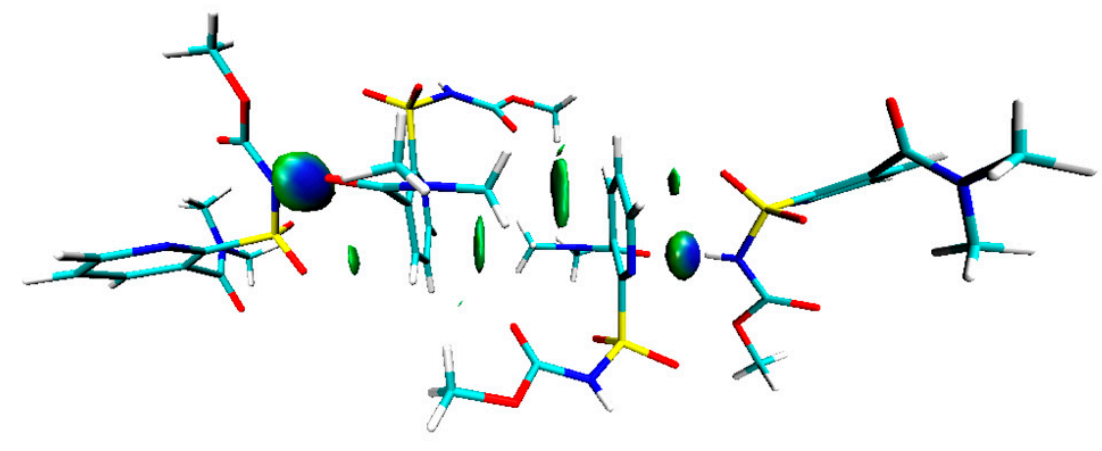

(b)

Figure 6. VMD figures on the basis of independent gradient model (IGM) analysis of different molecules in (a) NS-MeOH and (b) PCM.

\subsection{AIM Analysis}

Atom-in-molecule (AIM) [40] analysis has been widely used to reveal the feature of hydrogen bonds, which was not only appropriate for a conventional intermolecular $\mathrm{H}$-bond but also applicable to an intramolecular H-bond [41]. In this case, this method was implemented to further evaluate the strength of H-bonds (N4-H4B $\cdots \mathrm{N} 2, \mathrm{O} 7-\mathrm{H} 7 \mathrm{~A} \cdots \mathrm{O} 6, \mathrm{~N} 3-\mathrm{H} 3 \mathrm{~A} \cdots \mathrm{O} 7)$ in NS-MeOH. Considering the influence of solvent effect on the H-bond interactions, two NS-methanol molecular pairs were analyzed in a gas phase and a liquid phase, respectively. Pair 1 contained $\mathrm{H}$-bonds of N3-H3A $\cdots \mathrm{O} 7$ and

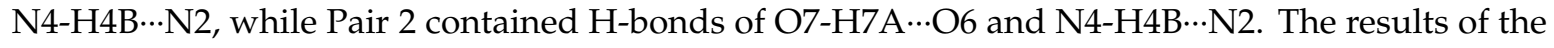


AIM topological path were shown in Figure 7 and the topological parameters of H-bonds were listed in Table 3.

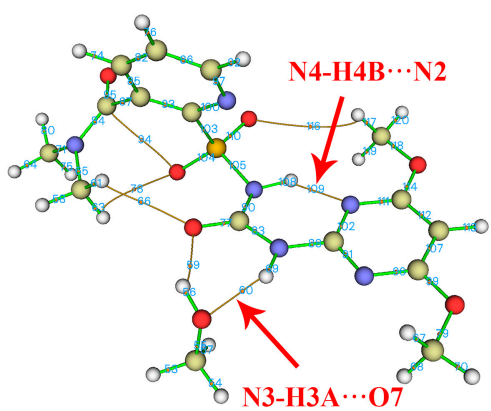

(a)

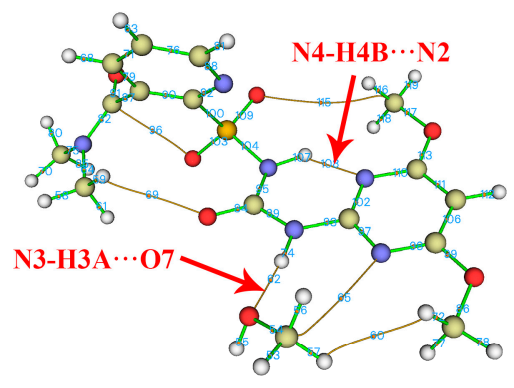

(c)

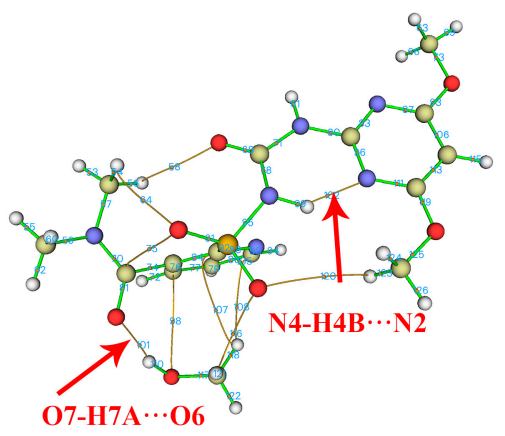

(b)

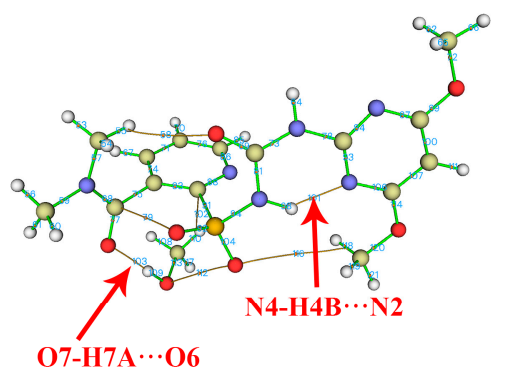

(d)

Figure 7. The AIM topological path maps of two NS-methanol pairs in different phases. (a) Pair 1 in the gas phase, (b) Pair 2 in the gas phase, (c) Pair 1 in the liquid phase, and (d) Pair 2 in the liquid phase. Small orange dots and thin orange lines indicated the bond critical point, H-bonds among atoms,

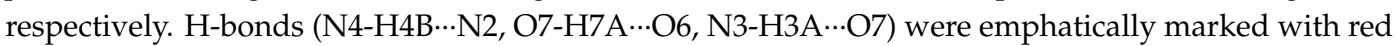
arrows, respectively.

Table 3. Topological parameters of H-bonds at $(3,-1)$ BCPs in two NS-methanol pairs in different phases.

\begin{tabular}{|c|c|c|c|c|c|c|c|}
\hline Phase & Complex & H-Bond & $\rho$ & $\nabla^{2} \rho$ & $\mathbf{H}$ & $\mathrm{V}$ & G \\
\hline \multirow{4}{*}{ gas } & \multirow{2}{*}{ a } & N3-H3A-..O7 & 0.0249 & 0.0940 & -0.0014 & -0.0219 & 0.0205 \\
\hline & & N4-H4B $\cdots \mathrm{N} 2$ & 0.0217 & 0.0813 & -0.0012 & -0.0160 & 0.0148 \\
\hline & \multirow{2}{*}{$\mathrm{b}$} & O7-H7A $\cdots$ O6 & 0.0270 & 0.1065 & -0.0016 & -0.0238 & 0.0222 \\
\hline & & N4-H4B $\cdots \mathrm{N} 2$ & 0.0213 & 0.0812 & -0.0014 & -0.0159 & 0.0145 \\
\hline \multirow{4}{*}{ liquid } & \multirow[b]{2}{*}{ C } & N3-H3A…07 & 0.0305 & 0.1164 & -0.0012 & -0.0287 & 0.0275 \\
\hline & & $\mathrm{N} 4-\mathrm{H} 4 \mathrm{~B} \cdots \mathrm{N} 2$ & 0.0228 & 0.0814 & -0.0013 & -0.0163 & 0.0150 \\
\hline & \multirow{2}{*}{$\mathrm{d}$} & O7-H7A $\cdots$ O6 & 0.0316 & 0.1172 & -0.0011 & -0.0290 & 0.0278 \\
\hline & & $\mathrm{N} 4-\mathrm{H} 4 \mathrm{~B} \cdots \mathrm{N} 2$ & 0.0229 & 0.0814 & -0.0013 & -0.0163 & 0.0150 \\
\hline
\end{tabular}

As shown in Figure 6, $(3,-1)$ bond critical points (BCPs) for H-bonds in two NS-methanol pairs in different phases were exhibited with orange lines and dots, which provides evidence of the multiple intermolecular and intramolecular interactions in NS-MeOH. According to the criterion proposed by Bader and Popelier [42], once the electron density $(\rho)$ and the Laplacian of the electron density $\left(\nabla^{2} \rho\right)$ values lies in the range ( $\rho: 0.002-0.035$ a. u., $\nabla^{2} \rho: 0.024-0.139$ a. u.), the interaction types between atoms can be identified as the H-bond. In addition, Rozas et al. [43] proposed to characterize the strength of $\mathrm{H}$-bonds based on the relationship among the $\nabla^{2} \rho$ and the energy density $(\mathrm{H})$ at the critical point of the bond. The interaction is weak H-bonds when $\nabla^{2} \rho>0$ and $\mathrm{H}>0$, and it is medium H-bonds when $\nabla^{2} \rho>0$ and $\mathrm{H}<0$, while strong $\mathrm{H}$-bonds show $\nabla^{2} \rho<0$ and $\mathrm{H}<0$. As shown in Table 3, it was clear that the $\rho$ and $\nabla^{2} \rho$ values of adjusted to range mentioned and $\mathrm{H}<0$, which indicates 
that three H-bonds can be ascribed to a medium H-bond. Since the $\rho$ value was positively related to the bond strength [44], the evidence that $\rho$ values of $\mathrm{H}$-bonds exhibited an increase in the sequence of N3-H3A $\cdots \mathrm{O} 7, \mathrm{~N} 4-\mathrm{H} 4 \mathrm{~B} \cdots \mathrm{N} 2, \mathrm{O} 7-\mathrm{H} 7 \mathrm{~A} \cdots \mathrm{O} 6$ whether in a gas phase or in a liquid phase, indicated O7-H7A $\cdots$ O6 H-bond was the strongest interaction of them, which was in line with the smallest $\mathrm{H}$-bond

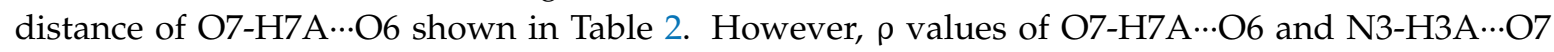

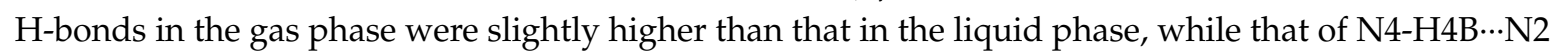
were approximately consistent in two phases, which indicates that the solvent effect had an influence

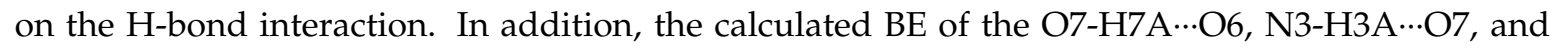
$\mathrm{N} 4-\mathrm{H} 4 \mathrm{~B} \cdots \mathrm{N} 2 \mathrm{H}-\mathrm{bonds}$ were $-6.3052 \mathrm{kcal} / \mathrm{mol},-6.0536 \mathrm{kcal} / \mathrm{mol}$, and $-4.3547 \mathrm{kcal} / \mathrm{mol}$, respectively.

\subsection{Hirshfeld Surface Analysis}

Hirshfeld surface analysis (HS) and the two-dimensional (2D) fingerprint plots [45] are powerful tools to elucidate the features of intermolecular interactions. To better understand the role of solvent molecules in the solvate formation, HS was performed based on CrystalExplorer 17.5 [46]. Moreover, the $d_{\text {norm }}$ surface is shown as transparent, which allows the NS group to be visible and highlights the acceptor and donor equally. With respect to NS-MeOH (Figure 8a), the results suggested that the

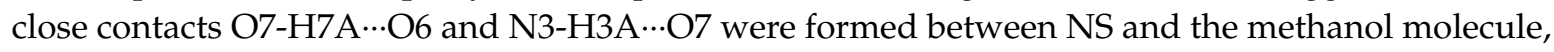
where the deeply red spots on the surfaces indicated the H-bonding contacts [47]. In addition, for further investigation of the interactions among NS and methanol molecules, 2D-fingerprint plots were performed. The relative contributions of dominant interactions of the NS molecule in NS-MeOH crystal forms were concluded in Figure 8b. The results indicated that the intermolecular $\mathrm{H} \cdots \mathrm{H}$ and $\mathrm{O} \cdots \mathrm{H}$ interactions making the greatest contribution to the $\mathrm{HS}$ were in proportion of $42 \%$ and $35.7 \%$, respectively, which could be ascribed to the formation of hydrogen bonds and the existence of other weak interactions involving $\mathrm{H}$ atoms on the surface. In addition, it was also found that there was a small proportion of $\mathrm{C} \cdots \mathrm{H}$ and $\mathrm{N} \cdots \mathrm{H}$ interaction comprising $6.6 \%$ and $8.8 \%$, respectively, which also played an important role in stabilizing the structure.

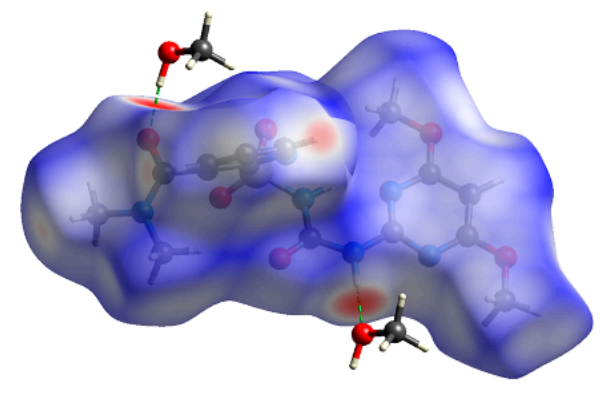

(a)

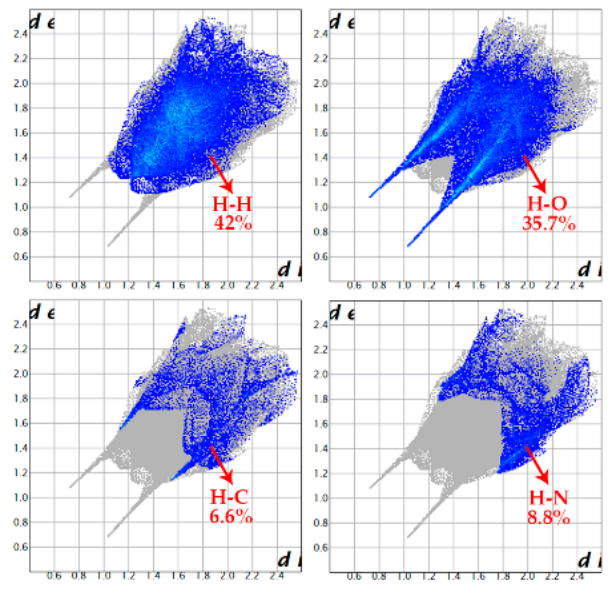

(b)

Figure 8. (a) Hirshfeld surface of the NS molecule in NS-MeOH. (b) 2D-fingerprint plots combined with the relative contributions of dominant interactions of the NS molecule in NS-MeOH.

\subsection{Thermal Analysis and Desolvation Study}

Thermal behaviors of NS-MeOH were inspected by TGA and DSC. The overlaid TGA-DSC profiles are summarized in Figure 9. It could be found that the desolvation of NS-MeOH corresponding to the first sharp endothermic peak in DSC thermograms occurred at $142{ }^{\circ} \mathrm{C}$, which was echoed in the 
weight loss stage in the TGA curves. Furthermore, the weight loss of the stage of desolvation obtained by TGA analysis was $6.7 \%$, which coincided with the theoretical value (7.2\%). NS-MeOH exhibited an unexpectedly higher $\mathrm{T}_{\text {onset }}\left(142{ }^{\circ} \mathrm{C}\right)$ than the boiling points of methanol. As mentioned before, it was attributed to the intensely intermolecular $\mathrm{H}$-bonds interaction between the host molecules and methanol molecules. Meanwhile, after the desolvation process, form VI previously reported in the literature [18] was obtained and verified by PXRD analysis (Figure S4). Afterward, with the temperature increasing, the second broad endothermic peaks between $156{ }^{\circ} \mathrm{C}$ and $176{ }^{\circ} \mathrm{C}$ suggested that the decomposition of form VI, which was consistent with the continuous weight loss in the TGA thermograms.

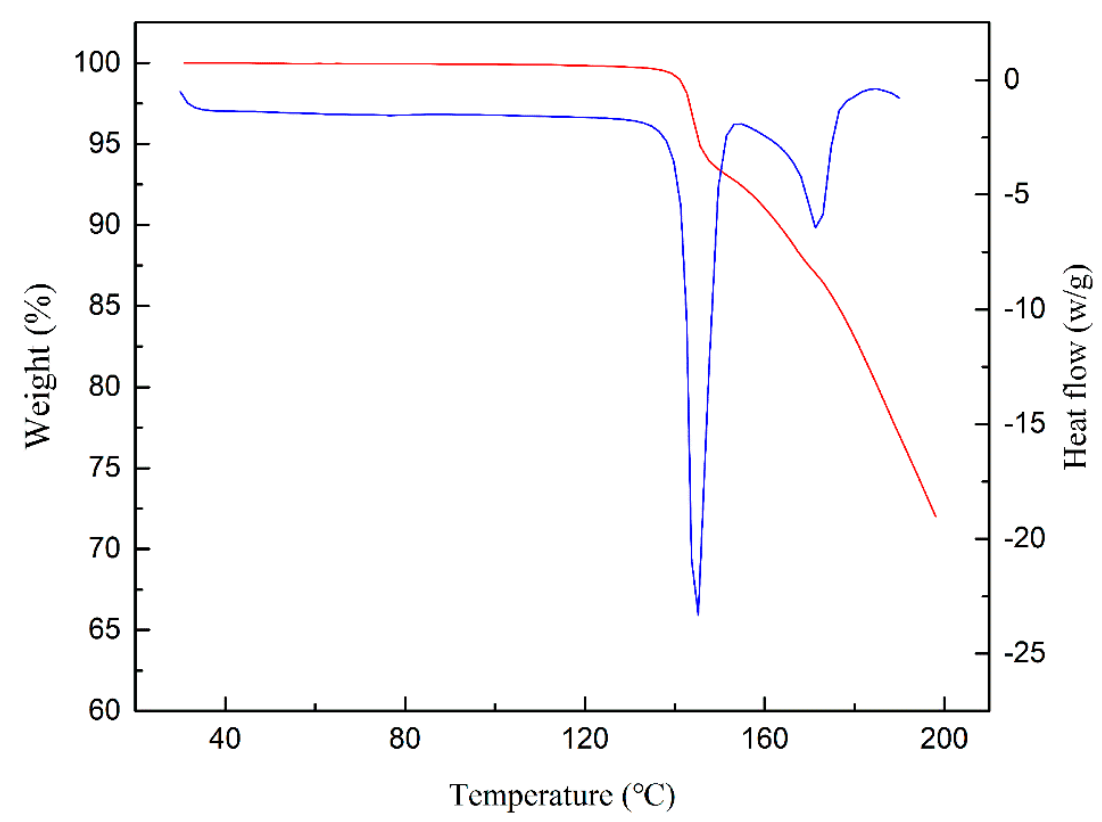

Figure 9. The overlaid thermogravimetric analysis (TGA) and differential scanning calorimetry (DSC) curves of NS-MEOH.

A single crystal has been considered as a representative example for the study on the phase transition of polymorph and the desolvation of solvate. Pal et al. [40] revealed the temperature-induced reversible first-order single crystal to a single crystal phase transition in Boc- $\gamma 4(\mathrm{R}) \mathrm{Val}-\mathrm{Val}-\mathrm{OH}$ through hot-stage microscopy (HSM). Yang et al. [41] found the desolvation of the single crystal of solvates of sorafenib tosylate converted to form I through HSM. To achieve comprehensive understanding of phase transformation phenomenon of NS-MeOH, HSM was established to provide deeper knowledge of the desolvation process at a heating rate of $10^{\circ} \mathrm{C} / \mathrm{min}$. As could be seen in Figure 10, a single crystal of NS-MeOH appeared to remain unchanged up to $130^{\circ} \mathrm{C}$. When heated to $140{ }^{\circ} \mathrm{C}$, the progressive loss of crystal transparency seemed to occur. Subsequently, defects were emerged from the interface, which follows the appearance of some tiny bubbles labelled by red arrows up to $145.7^{\circ} \mathrm{C}$, indicating the beginning of the event of desolvation. Upon further heating, it could be seen that methanol gradually escaped from the cracks marked with a red circle in the top left corner. At $150{ }^{\circ} \mathrm{C}$, the complete loss of transparency indicated the completion of the desolvation process. Nevertheless, the original shapes of the NS-MeOH was maintained. On the basis of the results of PXRD, TGA, and DSC discussed above, it could be determined that the NS-MeOH was converted to form VI after desolvation. Thus, a mechanism was proposed to explain the phenomenon. Methanol molecules escaped from the crystal lattice in the defective zones, and then the structural rearrangement occurred, which results in an anhydrous form analogous to the WET 3 model (water evolution type) classified by Andrew K. Galwey [48]. 


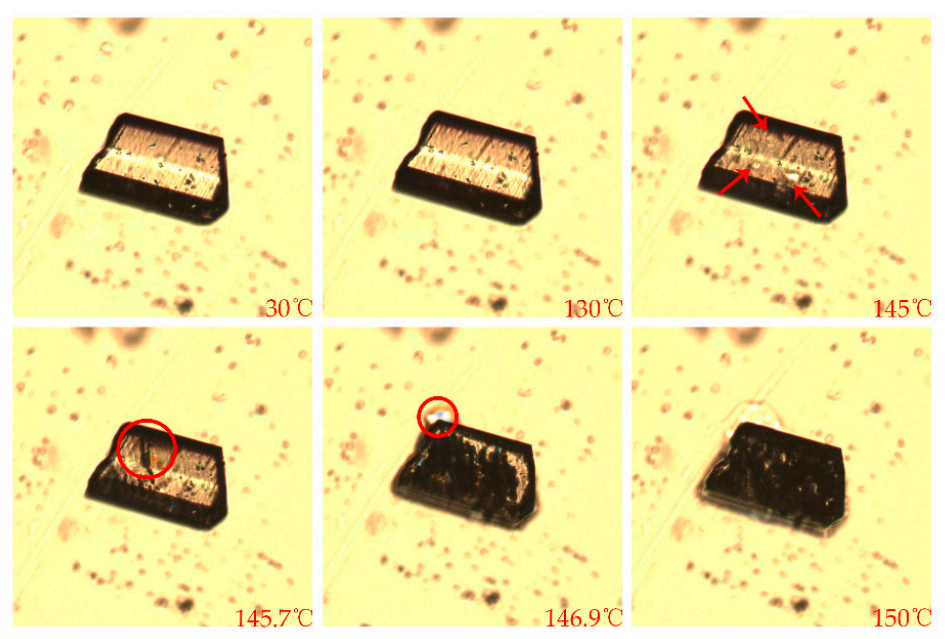

Figure 10. HSM images of NS-MeOH. The tiny bubbles and the cracks were pointed by red arrows and circles, respectively.

\subsection{Dissolution Behaviour}

Poor aqueous solubility of drugs has prevented their potentially widespread application. To meet the urgent needs in improving the bioavailability, much effort has been devoted to enhancing pharmaceutical solubility in aqueous solution from perspectives of cocrystal, polymorphism, and solvate [49]. It is noteworthy that different structures may lead to different physicochemical properties. Thus, it is of great value to compare the solubility among different solid forms. In this study, the dissolution behavior of NS and NS-MeOH was determined by the paddle method. In addition, the undissolved powders after the dissolution experiment were collected and analyzed by PXRD (Figure S4). The results of PXRD indicated that the undissolved powders of NS-MeOH and NS underwent a solution-mediated phase transformation to NS monohydrate [50-52]. The solubility versus time was depicted in Figure 11. Clearly, "spring and parachute" behavior was demonstrated in the dissolution profiles, which correspond to the process of solution-mediated phase transformation. The NS-MeOH achieved a maximum concentration of approximately $186.7 \mu \mathrm{g} / \mathrm{mL}$, which was 1.27 times of NS (147.1 $\mu \mathrm{g} / \mathrm{mL}$ ). This phenomenon proved that incorporation of methanol into the NS crystal lattice modified its structure, which resulted in better solubility of NS in water.

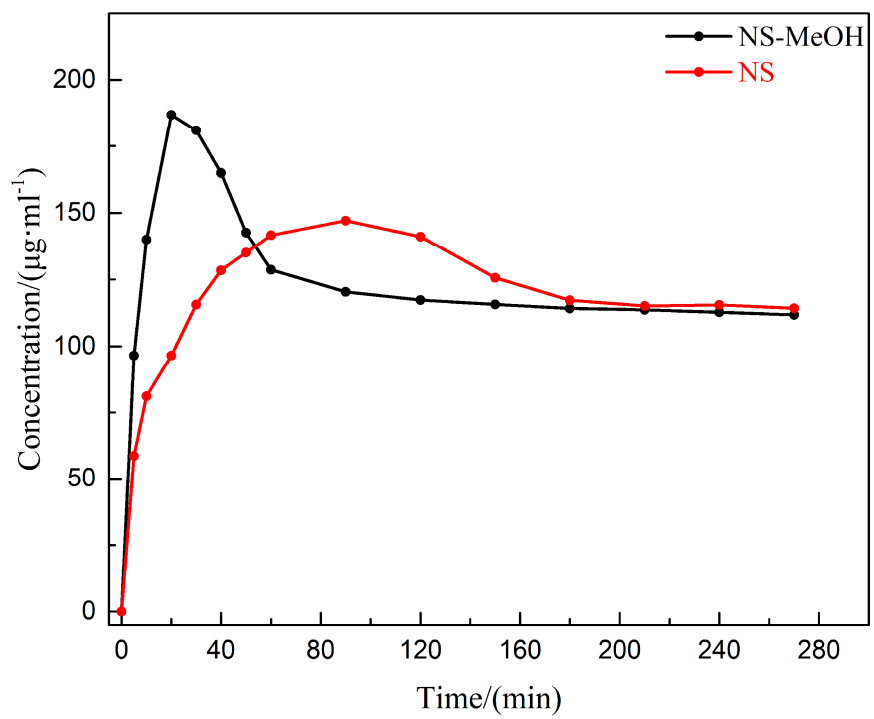

Figure 11. Plot of dissolution of NS and NS-MeOH. 


\subsection{Methanolysis of NS}

As Sabadie [20,53] described, the alcoholysis reaction appeared to be a characteristic of all sulfonylurea herbicides, involving the breakdown of the urea part of the molecule. In our study, the single crystal of PCM was obtained after heating the supersaturated methanol solution of NS. Thus, we could reach the conclusion that NS underwent a methanolysis reaction in which the corresponding products were PCM and aminopyrimidine, as shown in Figure 12. The results indicated that NS tended to form NS-MeOH at a lower temperature, while the methanolysis reaction occurred under heating. This could be explained by the methanolysis reaction, which needed to overcome a relatively higher activation energy barrier to dissociate the given covalent bond compared to the formation of hydrogen bonds.

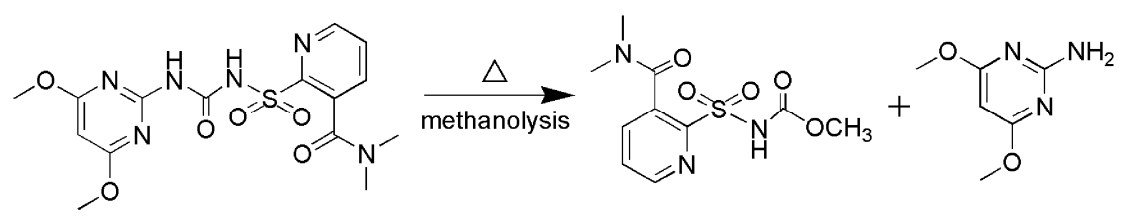

Figure 12. Methanolysis of NS.

\subsection{Herbicidal Activity}

The inhibition rates of NS, NS-MeOH, and PCM against weeds were listed in Table 4. The results showed that the growth inhibition rates of E. crusgalli, S. viridis, D. sanguinalis, and A. theophrasti for NS were $100 \%, 100 \%, 90 \%$, and $20 \%$, while, for NS-MeOH, were $100 \%, 90 \%, 85 \%$, and $30 \%$, and, for PCM, were $70 \%, 55 \%, 50 \%$, and $10 \%$, respectively, at the dosages of $37.5 \mathrm{~g}$ a.i./ha. Compared with NS, similar control efficacies against E. crusgalli, S. viridis, and D. sanguinalis, and a better control efficacy against $A$. theophrasti, especially, for nicosulfuron methanol solvates were achieved. However, there was a significant difference between NS and PCM. In contrast to NS, extreme lower inhibition rates of PCM against four kinds of weeds were exhibited. As the concentration increased to $150 \mathrm{~g}$ a.i./ha, the control efficacies against E. crusgalli, S. viridis, D. sanguinalis, and A. theophrasti for NS, NS-MeOH, and PCM, were $100 \%, 100 \%, 95 \%, 40 \%$, and $100 \%, 95 \%, 90 \%, 40 \%$, and $80 \%, 70 \%, 70 \%$, and $20 \%$, respectively. Although the control efficacies of $\mathrm{PCM}$ were promoted intensely, there was a relatively large gap between PCM and the remaining compounds. Thus, it was indicated that NS and NS-MeOH had similar herbicidal activities at the same experimental concentrations, which were more effective than PCM. In terms of structure, the results should be due to the breakage of a sulfonylurea functional group, which had great influence on herbicidal activity.

Table 4. The growth inhibition rates of E. crusgalli, S. viridis, D. sanguinalis, and A. theophrasti for NS, NS-MeOH, and PCM. (Inhibition rate/\%).

\begin{tabular}{cccccc}
\hline Compounds & $\begin{array}{c}\text { Concentration } \\
\text { (g a.i./ha) }\end{array}$ & E. crusgalli & S. viridis & D. sanguinalis & A. theophrasti \\
\hline \multirow{2}{*}{ NS } & 37.5 & 100 & 100 & 90 & 20 \\
& 150 & 100 & 100 & 95 & 40 \\
NS-MeOH & 37.5 & 100 & 90 & 85 & 30 \\
& 150 & 100 & 95 & 90 & 40 \\
PCM & 37.5 & 70 & 55 & 50 & 10 \\
& 150 & 80 & 70 & 70 & 20 \\
\hline
\end{tabular}

\section{Conclusions}

In this study, nicosulfuron methanol solvate (NS-MeOH) was found at a relatively lower temperature $\left(5^{\circ} \mathrm{C}\right)$, while PMC, which is a product of methanolysis of NS, was obtained when the reaction occurred under heating. A detailed description of the NS-MeOH structure combined 
with an independent gradient model (IGM) analysis and Hirshfeld surface analysis (HS) indicated that methanol molecules incorporated into the crystal lattice formed an H-bond with NS molecules, where the H-bond controlled the assembly of the molecules resulting in final packing motifs and also exerted great influence on physicochemical properties. In addition, it was concluded that

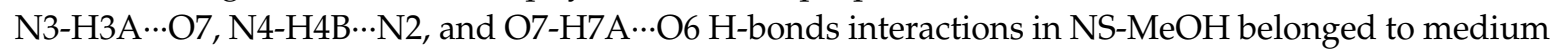
$\mathrm{H}$-bonds in terms of AIM analysis. The bonding energies of these main $\mathrm{H}$-bonds were also calculated. In consequence, the bonding energy of the O7-H7A $\cdots$ O6 H-bond was the strongest of them. By performing a comprehensive characterization of NS-MeOH desolvation, a proper mechanism of the phase transformations of NS-MeOH was proposed. Methanol molecules escaped from the crystal lattice in the defective zones, and then a structural rearrangement resulted in an anhydrous form. Moreover, it was found that NS and NS-MeOH had similar herbicidal activities at the experimental concentrations, while NS-MeOH exhibited better performance in solubility. Meanwhile, the herbicidal activity of products of methanolysis were also investigated. As a result, a methanolysis reaction led to the breakdown of the active group of the sulfonylurea bridge, which significantly reduced herbicidal activity of the corresponding product.

Supplementary Materials: The following are available online at http://www.mdpi.com/2073-4352/10/3/157/s1, Table S1: Crystallographic data of II, S1, S3, Hydrate and DMF solvate based on NS. Figure S1: Plot of UV standard curve for NS in aqueous. Figure S2: ORTEP view of NS-MeOH with atom labelling scheme. Figure S3: ORTEP view of PCM with atom labelling scheme. Figure S4: PXRD patterns of (a) NS. (b) Desolvation product of NS-MeOH. (c) Undissolved powders of NS after the dissolution experiment. (d) Undissolved powders of NS-MeOH after the dissolution experiment. (e) Simulated pattern of the NS hydrate.

Author Contributions: Conceptualization, W.C. and H.Z. Methodology, W.C., H.Z., and J.X. Software, W.C., H.Z., and J.X. Validation, W.C., H.Z., and J.X. Formal analysis, H.Z. and B.Z. Investigation, H.Z., B.Z., and D.W. Data curation, H.Z., B.Z., and D.W. Writing-original draft preparation, H.Z. and B.Z. Writing-review and editing, H.Z., B.Z., X.C., G.L., and W.C. Visualization, W.C. Supervision, W.C. Project administration, W.C. Funding acquisition, W.C. and L.Z. All authors have read and agreed to the published version of the manuscript.

Funding: The authors are grateful for the financial support from the National Key Research and Development Projects 2017YFD0201406, Major National Science and Technology Projects 2017ZX09101001, Major National Scientific Instrument Development Project of China 21527812, and National Natural Science Foundation of China 21706183.

Conflicts of Interest: The authors declare no conflict of interest.

\section{References}

1. Yuan, L.; Lorenz, H. Solvate Formation of Bis (demethoxy) curcumin: Screening and Characterization. Crystals 2018, 8, 407. [CrossRef]

2. Healy, A.M.; Worku, Z.A.; Kumar, D.; Madi, A.M. Pharmaceutical solvates, hydrates and amorphous forms: A special emphasis on cocrystals. Adv. Drug Deliv. Rev. 2017, 117, 25-46. [CrossRef] [PubMed]

3. Dey, D.; Thomas, S.P.; Spackman, M.A.; Chopra, D. Quasi-isostructural polymorphism' in molecular crystals: Inputs from interaction hierarchy and energy frameworks. Chem. Commun. 2016, 52, 2141-2144. [CrossRef] [PubMed]

4. Smith, J.R.; Xu, W.Z.; Raftery, D. Analysis of conformational polymorphism in pharmaceutical solids using solid-state NMR and electronic structure calculations. J. Phys. Chem. B 2006, 110, 7766-7776. [CrossRef]

5. Sokolov, A.N.; Swenson, D.C.; MacGillivray, L.R. Conformational polymorphism in a heteromolecular single crystal leads to concerted movement akin to collective rack-and-pinion gears at the molecular level. Proc. Natl. Acad. Sci. USA 2008, 105, 1794-1797. [CrossRef]

6. Haleblian, J.; McCrone, W. Pharmaceutical applications of polymorphism. J. Pharm. Sci. 1969, 58, 911-929. [CrossRef]

7. Zhao, S.; Wang, L.; Wu, S. Progress in the Research of Pharmaceutical Polymorph. Chem. Ind. Eng. 2018, 35, $12-21$.

8. Ferrari, E.S.; Davey, R.J.; Cross, W.I.; Gillon, A.L.; Towler, C.S. Crystallization in polymorphic systems: The solution-mediated transformation beta to alpha glycine. Cryst. Growth Des. 2003, 3, 53-60. [CrossRef] 
9. Price, C.P.; Glick, G.D.; Matzger, A.J. Dissecting the behavior of a promiscuous solvate former. Angew. Chem. Int. Ed. 2006, 45, 2062-2066. [CrossRef]

10. Scheiner, S. The Pnicogen Bond: Its Relation to Hydrogen, Halogen, and Other Noncovalent Bonds. Acc. Chem. Res. 2013, 46, 280-288. [CrossRef]

11. Hunt, P.A.; Ashworth, C.R.; Matthews, R.P. Hydrogen bonding in ionic liquids. Chem. Soc. Rev. 2015, 44, 1257-1288. [CrossRef] [PubMed]

12. Gentry, E.C.; Knowles, R.R. Synthetic Applications of Proton-Coupled Electron Transfer. Acc. Chem. Res. 2016, 49, 1546-1556. [CrossRef] [PubMed]

13. Nyman, J.; Day, G.M. Static and lattice vibrational energy differences between polymorphs. Crystengcomm 2015, 17, 5154-5165. [CrossRef]

14. Vippagunta, S.R.; Brittain, H.G.; Grant, D.J.W. Crystalline solids. Adv. Drug Deliv. Rev. 2001, 48, 3-26. [CrossRef]

15. Berzins, A.; Skarbulis, E.; Actins, A. Structural Characterization and Rationalization of Formation, Stability, and Transformations of Benperidol Solvates. Cryst. Growth Des. 2015, 15, 2337-2351. [CrossRef]

16. Li, Y.H.; Han, J.; Zhang, G.G.Z.; Grant, D.J.W.; Suryanarayanan, R. In situ dehydration of carbamazepine dihydrate: A novel technique to prepare amorphous anhydrous carbamazepine. Pharm. Dev. Technol. 2000, 5, 257-266. [CrossRef]

17. Ngoc, L.S. Process for the Interconversion of Two Separate Crystal Forms of a Herbicidal Pyridine Sulfonamide. U.S. Patent 5202439-A, 13 April 1993.

18. Liu, Y.; Jia, L.; Wu, S.; Xu, S.; Zhang, X.; Jiang, S.; Gong, J. Polymorphism and molecular conformations of nicosulfuron: Structure, properties and desolvation process. Crystengcomm 2019, 21, 2790-2798. [CrossRef]

19. Chen, L.; Zhou, L.; Zhang, X.; Yang, Y.; Zhang, S.; Yang, W.; Xie, C.; Hou, B.; Bao, Y.; Yin, Q. Crystal Structure Characterization, Independent Gradient Model Analysis, and Gas-Phase-Mediated Transformation of Nicosulfuron DMF Solvate and Hydrate. Cryst. Res. Technol. 2019, 54, 1800244. [CrossRef]

20. Sabadie, J. Nicosulfuron: Alcoholysis, chemical hydrolysis, and degradation on various minerals. J. Agric. Food Chem. 2002, 50, 526-531. [CrossRef]

21. Sheldrick, G.M. SHELXT-Integrated space-group and crystal-structure determination. Acta Crystallogr. A Found. Adv. 2015, 71, 3-8. [CrossRef]

22. Sheldrick, G.M. Crystal structure refinement with SHELXL. Acta Crystallogr. Sect. C Struct. Chem. 2015, 71, 3-8. [CrossRef] [PubMed]

23. Dolomanov, O.V.; Bourhis, L.J.; Gildea, R.J.; Howard, J.A.K.; Puschmann, H. OLEX2: A complete structure solution, refinement and analysis program. J. Appl. Crystallogr. 2009, 42, 339-341. [CrossRef]

24. Macrae, C.F.; Edgington, P.R.; McCabe, P.; Pidcock, E.; Shields, G.P.; Taylor, R.; Towler, M.; van De Streek, J. Mercury: Visualization and analysis of crystal structures. J. Appl. Crystallogr. 2006, 39, 453-457. [CrossRef]

25. Tan, Y.; He, H.; Liu, X.; Weng, J.; Tan, C. Synthesis and Herbicidal Activities of Novel Pyridine Substituted Pyrazole Diacylhydrazine Derivatives. Chin. J. Synth. Chem. 2018, 26, 727-732.

26. Clark, S.J.; Segall, M.D.; Pickard, C.J.; Hasnip, P.J.; Probert, M.J.; Refson, K.; Payne, M.C. First principles methods using CASTEP. Z. Kristallogr. 2005, 220, 567-570. [CrossRef]

27. Vanderbilt, D. Soft self-consistent pseudopotentials in a generalized eigenvalue formalism. Phys. Rev. B Condens. Matter 1990, 41, 7892-7895. [CrossRef]

28. Grimme, S. Semiempirical GGA-type density functional constructed with a long-range dispersion correction. J. Comput. Chem. 2006, 27, 1787-1799. [CrossRef]

29. Zhao, Y.; Truhlar, D.G. Density functionals with broad applicability in chemistry. Acc. Chem. Res. 2008, 41, 157-167. [CrossRef]

30. Grimme, S. Density functional theory with London dispersion corrections. Wiley Interdiscip. Rev. Comput. Mol. Sci. 2011, 1, 211-228. [CrossRef]

31. Zhao, Y.; Schultz, N.E.; Truhlar, D.G. Design of density functionals by combining the method of constraint satisfaction with parametrization for thermochemistry, thermochemical kinetics, and noncovalent interactions. J. Chem. Theory Comput. 2006, 2, 364-382. [CrossRef]

32. Frisch, M.J.; Trucks, G.W.; Schlegel, H.B.; Scuseria, G.E.; Robb, M.A.; Cheeseman, J.R.; Scalmani, G.; Barone, V.; Mennucci, B.; Petersson, G.A.; et al. Gaussian 09; Gaussian Inc.: Wallingford, CT, USA, 2009. 
33. Marenich, A.V.; Cramer, C.J.; Truhlar, D.G. Universal Solvation Model Based on Solute Electron Density and on a Continuum Model of the Solvent Defined by the Bulk Dielectric Constant and Atomic Surface Tensions. J. Phys. Chem. B 2009, 113, 6378-6396. [CrossRef] [PubMed]

34. Lu, T.; Chen, F. Multiwfn: A multifunctional wavefunction analyzer. J. Comput. Chem. 2012, 33, 580-592. [CrossRef] [PubMed]

35. Humphrey, W.; Dalke, A.; Schulten, K. VMD: Visual molecular dynamics. J. Mol. Graph. 1996, 14, 33-38. [CrossRef]

36. Emamian, S.; Lu, T.; Kruse, H.; Emamian, H. Exploring Nature and Predicting Strength of Hydrogen Bonds: A Correlation Analysis Between Atoms-in-Molecules Descriptors, Binding Energies, and Energy Components of Symmetry-Adapted Perturbation Theory. J. Comput. Chem. 2019, 40, 2868-2881. [CrossRef]

37. Chandran, S.K.; Nangia, A. Modulated crystal structure $\left(Z^{\prime}=2\right)$ of alpha-D-glucofuranose-1,2: 3,5-bis (p-tolyl) boronate. Crystengcomm 2006, 8, 581-585. [CrossRef]

38. Nangia, A. Conformational polymorphism in organic crystals. Acc. Chem. Res. 2008, 41, 595-604. [CrossRef]

39. Lefebvre, C.; Rubez, G.; Khartabil, H.; Boisson, J.-C.; Contreras-Garcia, J.; Henon, E. Accurately extracting the signature of intermolecular interactions present in the NCI plot of the reduced density gradient versus electron density. Phys. Chem. Chem. Phys. 2017, 19, 17928-17936. [CrossRef]

40. Bader, R.F.W. Principle of stationary action and the definition of a proper open system. Phys. Rev. B Condens. Matter 1994, 49, 13348-13356. [CrossRef]

41. Grabowski, S.J.; Sokalski, W.A.; Dyguda, E.; Leszczynski, J. Quantitative classification of covalent and noncovalent H-bonds. J. Phys. Chem. B 2006, 110, 6444-6446. [CrossRef]

42. Popelier, P.L.A.; Bader, R.F.W. The existence of an intramolecular C-H-O hydrogen bond in creatine and carbamoyl sarcosine. Chem. Phys. Lett. 1992, 189, 542-548. [CrossRef]

43. Espinosa, E.; Alkorta, I.; Elguero, J.; Molins, E. From weak to strong interactions: A comprehensive analysis of the topological and energetic properties of the electron density distribution involving $\mathrm{X}-\mathrm{H}$ center dot center dot center dot F-Y systems. J. Chem. Phys. 2002, 117, 5529-5542. [CrossRef]

44. Zhang, P.; Peng, P.; Hou, B.; Zhai, C. Hydrogen bond interactions of dopamine hydrochloride with urea. Phys. Chem. Liq. 2019, 57, 746-754. [CrossRef]

45. Spackman, M.A.; McKinnon, J.J. Fingerprinting intermolecular interactions in molecular crystals. Crystengcomm 2002, 4, 378-392. [CrossRef]

46. McKinnon, J.J.; Spackman, M.A.; Mitchell, A.S. Novel tools for visualizing and exploring intermolecular interactions in molecular crystals. Acta Crystallogr. Sect. B Struct. Sci. 2004, 60, 627-668. [CrossRef]

47. Zhang, X.; Zhou, L.; Wang, C.; Li, Y.; Wu, Y.; Zhang, M.; Yin, Q. Insight into the Role of Hydrogen Bonding in the Molecular Self-Assembly Process of Sulfamethazine Solvates. Cryst. Growth Des. 2017, 17, 6151-6157. [CrossRef]

48. Galwey, A.K. Structure and order in thermal dehydrations of crystalline solids. Thermochim. Acta 2000, 355, 181-238. [CrossRef]

49. Blagden, N.; de Matas, M.; Gavan, P.T.; York, P. Crystal engineering of active pharmaceutical ingredients to improve solubility and dissolution rates. Adv. Drug Deliv. Rev. 2007, 59, 617-630. [CrossRef]

50. Kitamura, M.; Abe, T.; Kishida, M. Mechanism for the release of the industrial biocide CMI from clathrate crystal. Chem. Eng. Res. Des. 2008, 86, 1053-1058. [CrossRef]

51. Kitamura, M.; Fujimoto, M. Release control of industrial biocide (CMI) using clathrate crystal with TEP. J. Cryst. Growth 2003, 256, 393-400. [CrossRef]

52. Aaltonen, J.; Heinanen, P.; Peltonen, L.; Kortejarvi, H.; Tanninen, V.P.; Christiansen, L.; Hirvonen, J.; Yliruusi, J.; Rantanen, J. In situ measurement of solvent-mediated phase transformations during dissolution testing. J. Pharm. Sci. 2006, 95, 2730-2737. [CrossRef]

53. Sabadie, J. Behavior of four sulfonylurea herbicides in the presence of hydroxy compounds. J. Agric. Food Chem. 2000, 48, 4752-4756. [CrossRef] [PubMed]

(C) 2020 by the authors. Licensee MDPI, Basel, Switzerland. This article is an open access article distributed under the terms and conditions of the Creative Commons Attribution (CC BY) license (http://creativecommons.org/licenses/by/4.0/). 